\title{
A case of McArdle's syndrome with a positive family history
}

\author{
T. D. R. HOCKADAY, J. A. DOWNEY, ${ }^{1}$ AND R. F. MOTTRAM ${ }^{2}$ \\ From the Department of the Regius Professor of Medicine, \\ Radcliffe Infirmary, Oxford
}

McArdle (1951) described the case of a man who from early childhood was unable to maintain exercise, because muscle pain and stiffness developed during it. He found that blood concentrations of lactate and pyruvate did not increase in the usual way after exercise in this patient and therefore deduced that there was a defective breakdown of muscle glycogen. Other patients with similar symptoms and biochemical abnormalities have been described and their skeletal muscle shown to lack phosphorylase (Mommaerts, Illingworth, Pearson, Guillory and Seraydarian, 1959; Schmid and Mahler, 1959; Pearson, Rimer and Mommaerts, 1961; Thomson, MacLaurin and Prineas, 1963; Rowland, Fahn, and Schotland, 1963). The excess glycogen observed in skeletal muscle in these cases is explicable by a method of glycogen synthesis via uridine nucleotides that does not involve phosphorylase (Leloir and Cardini, 1957).

The onset early in life and the associated enzymatic defect suggest a genetic abnormality in McArdle's syndrome, while its rarity and the involvement of only one enzyme implicate a single gene. However, only one detailed report of an affected family (Schmid and Hammaker, 1961) supported this hypothesis until two recent descriptions. Engel, Eyerman, and Williams (1963) reported a defect of phosphorylase in siblings whose symptoms appeared only late in life, while Rowland et al. (1963) described a patient with a typical history of muscle pain and myoglobinuria who had one first cousin who complained of muscular arching and dark urine occasionally. Although the parents of their patient were themselves first cousins, none of his four sibs were affected. Also, Mahler stated (Schmid and Mahler, 1959) that among six patients whom he had seen with the clinical and biochemical findings of McArdle's syndrome there were two sisters in whom muscle studies had not been possible.

'Present Address: Columbia-Presbyterian Medical Center, 622 West 168th Street, New York 32, N.Y.

${ }^{2}$ University College of South Wales, Newport Road, Cardiff, Wales.
The present case is reported both because then history of symptoms in the patient's sister furthe supports the hypothesis of a genetic abnormality and because the patient is still only mildly afflicted? despite symptoms for over $\mathbf{4 0}$ years.

\section{CASE HISTORIES}

CASE 1 Mr. H.K., age 51 years, a draughtsman, has ha⿳亠丷厂 pain in the thighs and calves on exercise for as long as he can remember. He recalls that, even before the age of 10 years, he was unable to sprint in school races for moreu than 40 yards, being slower (or even stopped) after Ti $_{00}$ because of pain in the legs; he had similar symptomsip longer races, but might travel further because of a sloge? starting pace.

His symptoms were least troublesome between 13 and 18 years of age, but have since become more severe particularly during the last 10 years. As a young mane played cricket, but about 15 years ago he began to be out frequently because he had to stop during a secō\$ run. He has continued to play tennis with some succeses in local tournaments, although he now plays 'doubles only. He has had increasing difficulty in travelling homs from work in the last four years. Until 1962 (when he moved house) he bicycled four miles to the station and walked a few hundred yards at the other end of hs journey, all usually without discomfort. After work when he hurried to catch a train (and now had to cross bridge) he became so incapacitated that sometimes he was unable to board the train without help.

His symptoms differ with the exercise performed. After walking, the pain and weakness are chiefly in the calves. while after running the quadriceps are also affected; theses latter alone hurt after bicycling. In the last three years, he has had pain around the scapulae on hoeing his garde or towelling his back. During the last 10 years, the pain on walking has been more easily induced-with less hurry and on more gradual slopes. He can walk an unlimited distance on the flat at his own pace but his wif has to slow down when they walk together.

The two legs have been equally affected. His sympton are unrelated to the times of meals, to the weather, or to his emotions. He is perhaps more likely to suffer symptonks? late in the day, and considerable exercise on the previong day, e.g., after the first day of gardening in spring, 
an aggravating factor, and so is sexual intercourse the previous night. Unlike previously described patients, he has not noticed worsening during mild infections (McArdle, 1951) or improvement after drinking alcohol (Mellick, Mahler, and Hughes, 1962); he does not smoke.

When pain occurs on exercise, it usually continues and worsens until he rests, but occasionally mild pain has disappeared despite continued exercise. After one attack of pain and the consequent rest, his ability to exercise is often slightly greater. He usually stops exercising because of pain; but if he disregards this, he is then stopped by a feeling of weakness. None of his muscles are weak when unexercised. His muscles do not knot in a cramp, but he has thought that affected muscles are unduly firm after an attack. He has noticed no change in the colour of his urine after muscle pain.

He has had no other symptoms, and no serious illness. His weight has been steady around $160 \mathrm{lb}$. for the last 12 years. He has always been a big eater, like the patients of McArdle (1951) and Pearson et al. (1961).

His mother, aged 80 , is alive and well, but his father died in his sixties, probably of a heart attack. Their families were unrelated. One sister died with convulsions, aged 18 months. Two sisters are alive, of whom one is well but the younger has pain on exercise and is described below. His wife and only child, a 16-year-old girl, are both well.

On examination, Mr. H.K. appeared healthy, $5 \mathrm{ft} .7 \mathrm{in}$. tall, and weighed $159 \mathrm{lb}$. He had a moderate dorsal kyphosis with a deep chest antero-posteriorly but a normal expansion on inspiration. Subcutaneous fat felt normal in amount. Pulses were normal, blood pressure $145 / 85 \mathrm{~mm}$. $\mathrm{Hg}$, normal heart size and sounds, and there was no enlargement of the liver. The limbs were neither wasted nor weak, provided that strength in repetitive exercises was not tested, and trunk musculature was normal. Tendon reflexes were normal except that both ankle jerks, though present, were diminished. No fasiculation was seen, and there was no myotonia. Sensation was intact.

CASE 2 Miss M.K., age 44 years, a shop assistant, is the younger sister of Mr. H.K. She lives with her aged mother. She has been reluctant to undergo special examination or venepuncture to help to establish the nature of symptoms which are only mildly disturbing to her. However, she kindly sent two written descriptions of her symptoms.

She feels discomfort only when she hurries, walks up a slope, or climbs stairs. She has felt the discomfort more in the legs than elsewhere; and she wrote: 'The back of the knee goes first, a sort of tightening of the muscles, and then in the thigh.' She has similar though milder sensations in the arms, but again only on hurried effort.

She first noticed the discomfort on climbing a hill to school in early childhood. She has noticed pain more in recent years, but feels that this is because she does more as her mother ages. Discomfort occurs when she sets out to walk to the bus stop, but after resting she can walk more easily - 'I can walk quickly or even run'. Similarly, although her arms 'go limp' shortly after she starts to mow the lawn, after a brief rest she can finish the job without difficulty if she does not hurry. She feels that she becomes more breathless on exercise than others, 'as though I had done extra'. Meals make no difference to her symptoms.

Her general practitioner, Dr. W. G. Toole, has noticed no abnormalities of her limbs at rest, and none were observed when she was in hospital in 1961 for repair of a hernia.

\section{INVESTIGATION OF CASE 1}

Mr. H.K. sought medical advice for his symptoms many times, but was not admitted to hospital until 1960. Investigation then showed normal haemoglobin, white cell count, and E.S.R.; normal plasma sodium, potassium, and chloride concentrations; and a normal femoral arteriogram on the right. It was concluded that there was no generalized abnormality of muscle metabolism, because muscle pain could not be produced in the arms by exercise unless arterial blood was cut off by an inflated cuff.

Four months later, the patient was referred to Professor Pickering, to whom the early onset of symptoms and the family history suggested a congenital abnormality. Accordingly, further studies were performed.

Measurement of blood flow by plethysmography (Lewis and Grant, 1925) established that this was normal in the legs. The flow at rest was normal (average $5.1 \mathrm{ml}$./ $100 \mathrm{ml}$. tissue $/ \mathrm{min}$. for 23 successive observations of five seconds each with a similar rest period between; plethysmograph temperature $33.8^{\circ} \mathrm{C}$.). After an interval of five min., an arterial occlusion cuff was maintained around the thigh for five min. and blood flow measurements restarted 10 seconds after its release. The first five readings averaged $36 \mathrm{ml} . / 100 \mathrm{ml}$. tissue $/ \mathrm{min}$. (individual values decreased progressively from 51 to 26 ) and it was not until the twelfth period that flow returned to control values, two min. after release of the cuff. Thus, blood flow increased normally to the stimulus of tissue ischaemia. It was similarly shown to be normally increased after exercise.

Subsequent observations were made with the diagnosis of McArdle's syndrome in mind. They are described in the order in which they were made; they were spread over many months since they were all done when Mr. H.K. was able to travel to Oxford in his spare time.

\section{METHODS}

Blood flow was measured in the right calf by venous occlusion plethysmography (Lewis and Grant, 1925). A forearm plethysmograph chamber was used in the estimation of changes in forearm volume after exercise.

Venous blood predominantly from exercised muscle was obtained by passing a catheter into a suitable antecubital vein and threading it peripherally so that it went deeply towards the muscular compartment (Mottram, 1955; Mottram and Butterfield, 1961). The position of the catheter was shown to be satisfactory before each experiment by taking $x$-ray pictures while it contained a radioopaque stylette. A cuff around the wrist was inflated to prevent venous drainage from the hand mixing with the blood drawn for examination. When changes in the blood 
from muscle that had done ischaemic work were to be examined, the first sample (after the work) was drawn before the occluding cuff on the upper arm was deflated. To provide comparable conditions, all other samples were drawn one minute after inflation of the arterial occlusive cuff around the upper arm and of the venous occlusive cuff around the wrist. Work was done on a dynamometer constructed so that the muscular contraction was almost isometric.

In the first test of ability to exercise to the point of incapacitating pain (Table IV) the patient mounted two steps, each 9 in. high. In time with a metronome, the patient climbed each step, making a movement every second so that it took $4 \mathrm{sec}$. to climb the two steps. He then stepped backwards to the ground with similar timing. After he was forced to stop by pain, he rested for $15 \mathrm{~min}$. before exercising again. The second test of exercise tolerance was conducted similarly, but at a slightly faster pace (Table V) and with the rest periods described.

The following methods were used for the chemical determinations:-Blood glucose, by the glucose oxidase method of Huggett and Nixon (1957); blood fructose, Weichselbaum, Margraf, and Elman (1953); blood lactate, Barker and Summerson (1941); blood pyruvate by chromatographic separation of the 2:4 dinitrophenyldrazone derivative in an acid system in which the cis and trans isomers form a single band (Hockaday, 1961); muscle glycogen by hydrolysis with potassium hydroxide and then hydrolysis of the residual 'glucose' polysaccharides with fluorometric measurement of the activity produced when o-anisine reacts with the glucose so produced (Seifter, Dayton, Novic, and Muntwyler, 1950); serum potassium by flame photometry; blood $p \mathrm{H}$ with a glass electrode (Cambridge $\mathrm{pH}$ meter and an Electronics Instrument Ltd. mercuric chloride-potassium chloride glass electrode (Wynn model) $)$ at $37 \cdot 1^{\circ} \mathrm{C}$.; blood creatine and creatinine (Brod and Sirota, 1948); and plasma myoglobin by spectroscopy.

\section{OBSERVATIONS}

DISTRIBUTION OF THE MUSClE ABNORMALITy A sphygmomanometer cuff around the right upper arm was inflated to $200 \mathrm{~mm}$. $\mathrm{Hg}$. Two seconds later the patient began to squeeze as hard as he could on a firm cylinder (diameter of cross-section $=1 \frac{1}{4}$ in.) in time with a metronome so that he maintained a maximal contraction for $1 \mathrm{sec}$. and then rested for $1 \mathrm{sec}$. before the next contraction. He could continue this exercise for only $50 \mathrm{sec}$. while four control subjects, including one older than the patient, could all continue for more than 80 seconds. It was concluded that, despite lack of symptoms, the forearm muscles as well as the obviously affected leg muscles were abnormal.

NATURE OF THE PAIN ON EXERTION After maximal contractions of the flexors of the fingers, when their arterial circulation was cut off, had produced pain in the forearm, the pain disappeared within $\frac{\mathbb{D}}{\bar{C}}$ six seconds of deflating the cuff around the upper arm. The cuff was reinflated to $200 \mathrm{~mm}$. $\mathrm{Hg}$ one $\mathrm{Z}_{\mathrm{D}}$ minute later and the pain gradually returned with $\overline{ }$ increasing intensity to reach its previous level afteres 30 seconds; it remained at this level for the next twQ minutes until free circulation was permitted when it again disappeared within 10 seconds.

The pain the patient experienced in his legs on? exercise with circulation intact was of the same deep diffuse, and severe type that he felt on exercising anischaemic limb, but was slower in onset. The symptoms resembled the ischaemic pain in normal subjects described by Lewis, Pickering, and Roths $\frac{-}{0}$ child (1931) in that it persisted so long as the circula- $\frac{\bar{c}}{\bar{c}}$ tion was occluded and disappeared within five to $10 \mathrm{sec}$. of restoring circulation, however long this was after the exercise stopped; and in its return if, within a few minutes of restoring normal blood flow, the circulation was again interrupted.

MUSCLE SWELLING In the case later described by Schmid and Mahler (1959), Kreutzer, Strait, and Kerr (1948) noted myoglobinuria after painfưं exercise and hardening of the muscles for as long $\$$ isi two hours after exertion. McArdle's patient (1939) also had similar prolonged hardening of his muscles. Mr. H.K. never complained of any sudden hardening of affected muscles, as in a cramp, but he said the $\mathrm{t}^{-}$ after painful exercise, especially if frequently repeated, his muscles would feel unusually hard aơd perhaps swollen. Certainly, after he had exercisecta forearm to the limit of pain and weakness with circulation occluded, the muscles felt firmer than those of the unexercised side, both before and aftero restoring the circulation. But measurements of fore arm volume, both by displacement of water from bucket and, on a second occasion, continuously by? plethysmography, indicated no greater swelling in the patient than in a control and that the rate of subsidence of the swelling was approximately the same in the two subjects.

\section{TABLE I}

EFFECT OF LEG EXERCISE FOR TWO MINUTES ON ARM VENOUS BLOOD

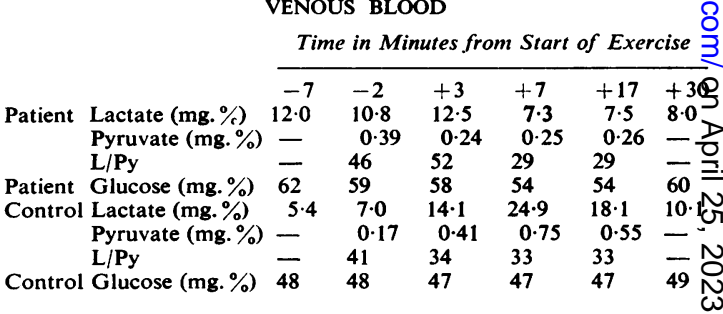




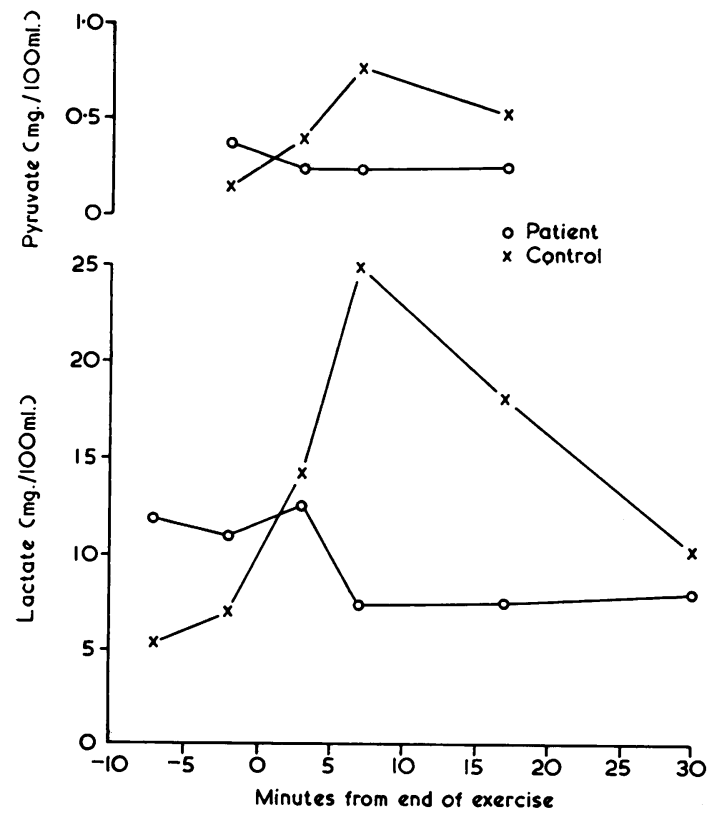

FIG. 1. Effect of leg exercise for $2 \mathrm{~min}$. on arm venous blood.

GLUCOSE, LACTATE, AND PYRUVATE IN ARM VENOUS BLOOD AFTER LEG EXERCISE Mr. H.K. twice walked down and ran up two flights of stairs. At the end of this exercise, he had severe pain in both thighs and difficulty in flexing his hips or extending his knees. As shown in Table I and Fig. 1, there was no increase in the concentrations of lactate, pyruvate, or glucose in blood from a forearm vein after this exercise, while a control subject, after similar exercise, showed the expected increase of lactate and pyruvate and no rise of glucose.

MEASUREMENT ON BLOOD FROM EXERCISED MUSCLE Forearm muscles were exercised isometrically while the arterial supply was occluded, and blood samples

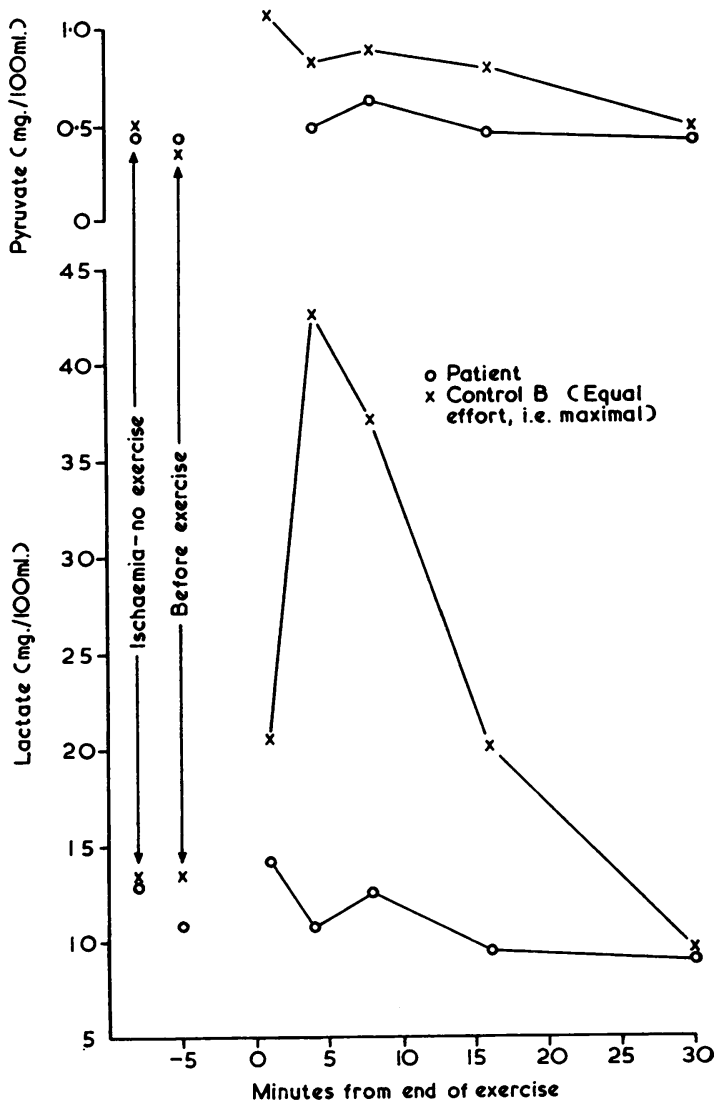

FIG. 2. Effect of forearm exercise on arm venous blood, the patient and control working as hard as they could.

were taken from a vein draining the deep structures of the forearm. A dynamometer tracing measured the work done. In the patient and one control a maximal effort was made with the ischaemic muscle while in the second control the work done was judged

TABLE II

EFFECT OF FOREARM EXERCISE ON VENOUS BLOOD FROM THE FOREARM

\begin{tabular}{|c|c|c|c|c|c|c|c|c|}
\hline & & Ischaemia & Before & Time & in.) fron & End of & rercise & \\
\hline & & Without Exercise & Exercise & 1 & 4 & 8 & 16 & 30 \\
\hline Patient & $\begin{array}{l}\text { Lactate (mg. \%) } \\
\text { Pyruvate (mg. \%) }\end{array}$ & $\begin{array}{c}13 \cdot 6 \\
0.47\end{array}$ & $\begin{array}{l}10 \cdot 8 \\
0.44\end{array}$ & $14 \cdot 2$ & $\begin{array}{c}10 \cdot 7 \\
0 \cdot 49\end{array}$ & $\begin{array}{c}12 \cdot 4 \\
0.60\end{array}$ & $\begin{array}{l}9 \cdot 3 \\
0 \cdot 45\end{array}$ & $\begin{array}{l}8 \cdot 8 \\
0 \cdot 43\end{array}$ \\
\hline & $\mathbf{L} / \mathbf{P y}$ & 29 & 25 & - & 22 & 21 & 21 & 20 \\
\hline & Creatinine (mg. \%) & 1.6 & $1 \cdot 5$ & - & $1 \cdot 7$ & $1 \cdot 7$ & - & - \\
\hline & Creatine (mg. \%) & 0.6 & 0.5 & - & $0 \cdot 8$ & $0 \cdot 8$ & - & - \\
\hline Control A (equal work) & Lactate (mg. \%) & $19 \cdot 2$ & $7 \cdot 0$ & $9 \cdot 1$ & $21 \cdot 2$ & $15 \cdot 5$ & $9 \cdot 8$ & $7 \cdot 2$ \\
\hline & Pyruvate (mg. \%) & 0.53 & 0.35 & 0.42 & 0.58 & 0.82 & 0.70 & 0.46 \\
\hline & $\mathbf{L} / \mathbf{P y}$ & 36 & 20 & 22 & 37 & 19 & 14 & 16 \\
\hline & Creatinine (mg. \%) & $1 \cdot 3$ & $1 \cdot 2$ & $1 \cdot 3$ & - & $1 \cdot 4$ & - & - \\
\hline & Creatine (mg. \%) & 0.6 & 0.4 & 0.6 & - & 0,5 & - & - \\
\hline Control B (equal effort, i.e., maximal) & Lactate (mg. \%) & $13 \cdot 3$ & $13 \cdot 4$ & $20 \cdot 6$ & $42 \cdot 5$ & $37 \cdot 2$ & $20 \cdot 0$ & $9 \cdot 6$ \\
\hline & Pyruvate (mg. \%) & 0.48 & $0 \cdot 38$ & 1.06 & 0.80 & 0.85 & 0.76 & 0.49 \\
\hline & $\mathbf{L} / \mathbf{P y}$ & 28 & 35 & 19 & 53 & 44 & 26 & 20 \\
\hline
\end{tabular}




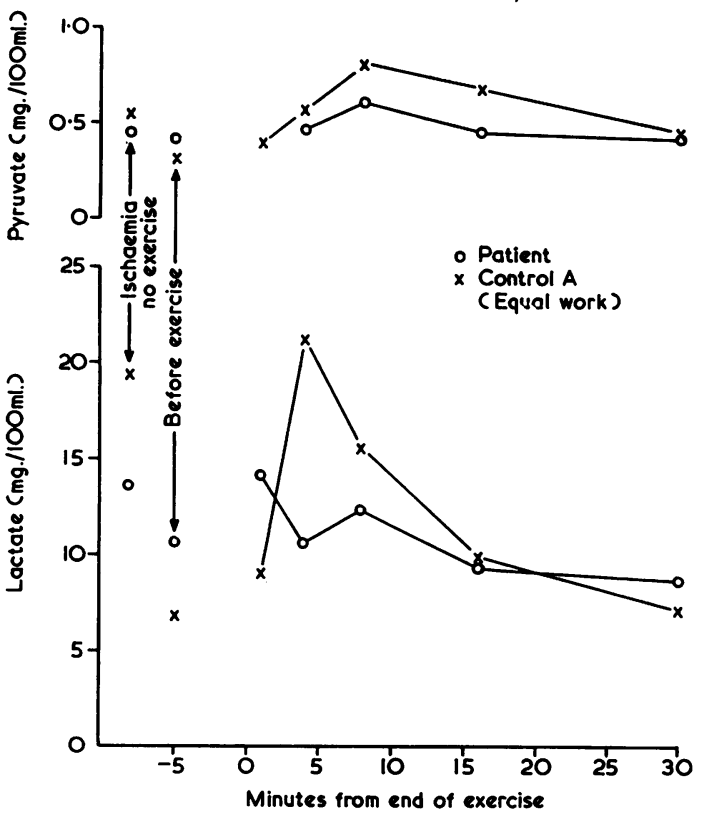

FIG. 3. Effect of forearm exercise on arm venous blood when the patient and control did approximately the same work.

so as to be approximately equal to that done by the patient. Blood was collected at intervals after the circulation had been restored at the end of exercise. Again, as shown in Table II and Figs. 2 and 3, the patient had no increase in blood lactate level, and probably no rise in blood pyruvate, while the glucose decreased slightly. In contrast, in both control subjects, the blood lactate and pyruvate concentrations both increased. This increase was greater when a maximal effort was made (Fig. 2) than when the work done was limited approximately to that done by the patient (Fig. 3).

Forearm venous blood from both the patient and the one control investigated showed a slight rise in serum creatine and creatinine after exercise. No myoglobinaemia occurred in either, nor did the patient have myoglobinuria after more strenuous exercise. No marked or systematic changes in plasma potassium or blood $p \mathrm{H}$ occurred in either subject during the experiment.

ELECTROMYOGRAPHY Dr. Geoffrey Rushworth found no abnormality of muscle at rest or when weakly contracted, but there was abnormal activity after strenuous work which was intensified by occluding the circulation.

Before exercise, recordings taken from co-axial needle electrodes within the left finger flexors and extensors and from the left deltoid (in the region later biopsied) showed action potentials whose mean amplitude was normal (maximum $3,000 \mu \mathrm{v}$.) and whose mean duration was also normal (forearm muscles 9 msec.. deltoid $14 \mathrm{msec}$.). In the deltoid many polyphasic units were found, but aparE from this there was no evidence of any myopathice process.

Simultaneous recordings were taken from the finger flexors and extensors during dynamometry ow. repeated gripping. When muscular spasm, pain, and weakness developed, considerable electrical activity persisted in the muscle long after the cessation of ? mechanical effort. (It was not, however, the tetanic type of electrical activity seen in ordinary muscular cramp or the cramp of tetany.) When the work wass performed with the circulation occluded, the low frequency discharge of motor units persisted in bothe flexors and extensors until the circulation was restored.

MUSCLE BIOPSY A piece of muscle $4 \times 3 \times 2 \mathrm{~cm} \stackrel{\text { ? }}{\circ}$ was taken from the left deltoid. The muscle was? examined microscopically by Dr. B. Brownello who found the most striking abnormality to be a granular necrosis of many fibres (or of segments of fibres, in which case there was a sharp boundatyoo between vital and necrotic sarcoplasm) (Fig. (5). The granular material stained with Best's carmife? (though not after diastase treatment) and some ofit $\vec{c}$ was also positive to periodic acid-Schiff; it was rots confined to sarcolemmal sacs as some lay free in $\mathrm{e}^{\mathrm{D}}$ tissue spaces. There was vacuolar degeneration $\vec{\Phi} \overrightarrow{\mathrm{f}}$ some fibres. There was no inflammatory infiltrate phagocytosis. The muscle fibres which appearedo normal with haematoxylin-eosin stained mores deeply with Best's carmine than did muscles from control subjects (rectus muscle removed undern general anaesthesia at abdominal operation on patients without debilitating illness) (Fig. 5). Silver impregnation of nerve fibres was normal. No abnor-0 mal sudanophil lipid was seen. With Dr. Bradbury of the Department of Human Anatomy, Oxford University, Dr. Brownell examined some of the muscle for phosphorylase activity (Takeuchi and Kuriaki, 1955). The patient's muscle showed a very? low level of phosphorylase while control muscles examined at the same time showed perhaps seven times as much.

The biopsy tissue was also examined by Dr. P? Kent. The glycogen content averaged $42 \cdot 3 \mathrm{mg}$./g. 음 wet wt. of tissue or $186 \mathrm{mg}$./g. dry wt. while rectus muscle from controls averaged $7.0 \mathrm{mg}$./g. wet wt or $25.5 \mathrm{mg}$./g. dry wt. Also, Dr. Kent incubated pieces of muscle with glucose-1-phosphate in citrate buffer (Sutherland and Wosilait, 1956), and foundo the rate of formation of inorganic phosphate to bew 


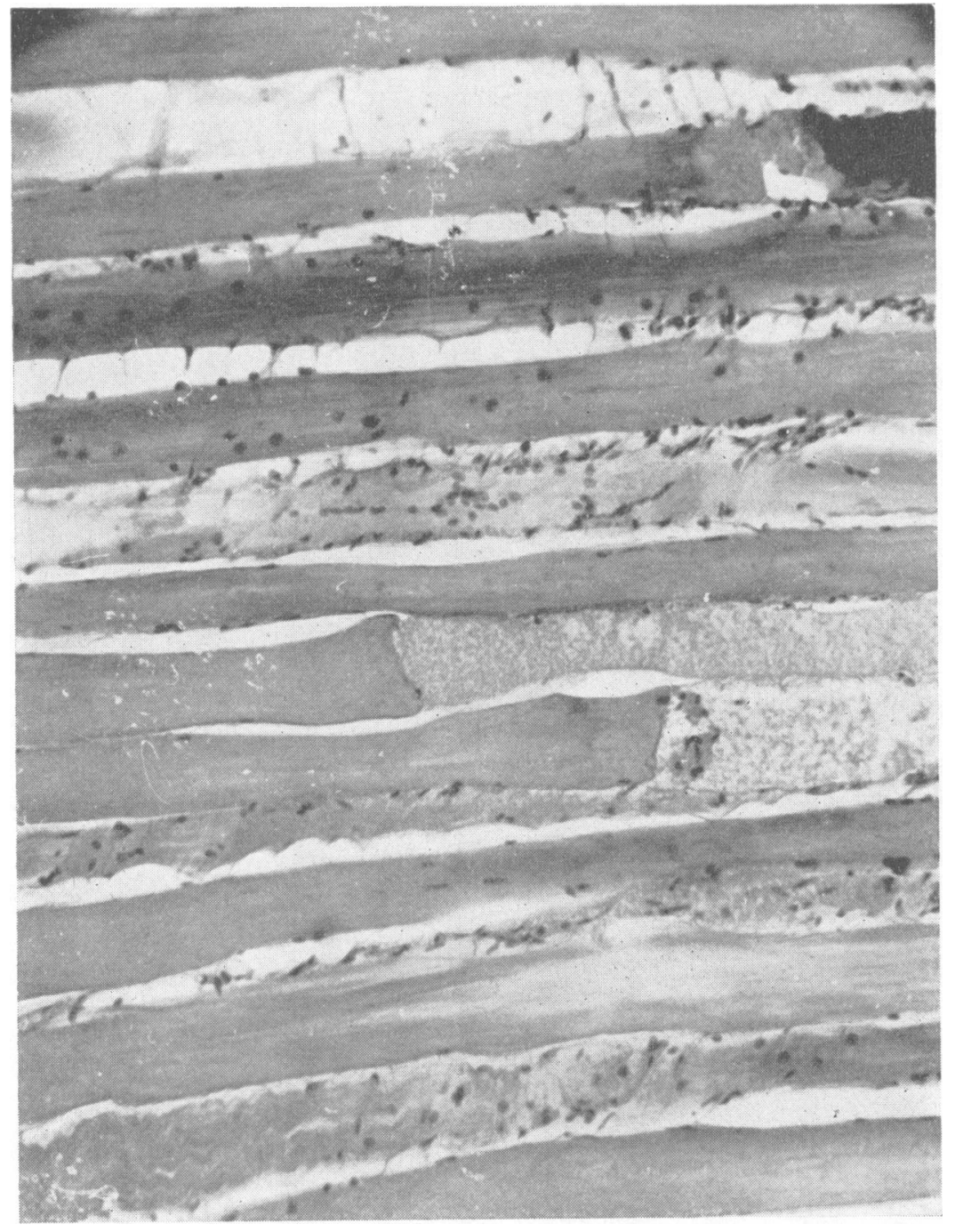

FIG. 4. Longitudinal section of biopsy specimen from deltoid muscle (patient 1). Stained haematoxylin and eosin. $\times 162$.

TABLE III

2 and $9 \mathrm{mM} / \mathrm{mg}$. dry wt. tissue $/ 15 \mathrm{~min}$. for muscle from the patient and two control subjects respectively, again indicating deficiency of phosphorylase in the patient's muscle.

FOREARM BLOOD FLOW DURING INFUSION OF ADRENALINE Professor H. Barcroft suggested that it would be interesting to study the effect of adrenaline infusion on muscle blood flow in a patient with a marked deficit of muscle phosphorylase, and this was done in cooperation with him. As shown in Fig. 6, infusion intravenously of $5 \mu \mathrm{g}$. of adrenaline per minute in saline solution for $10 \mathrm{~min}$. was followed by changes in blood flow very similar to those seen in a normal subject. In particular, the early and marked 


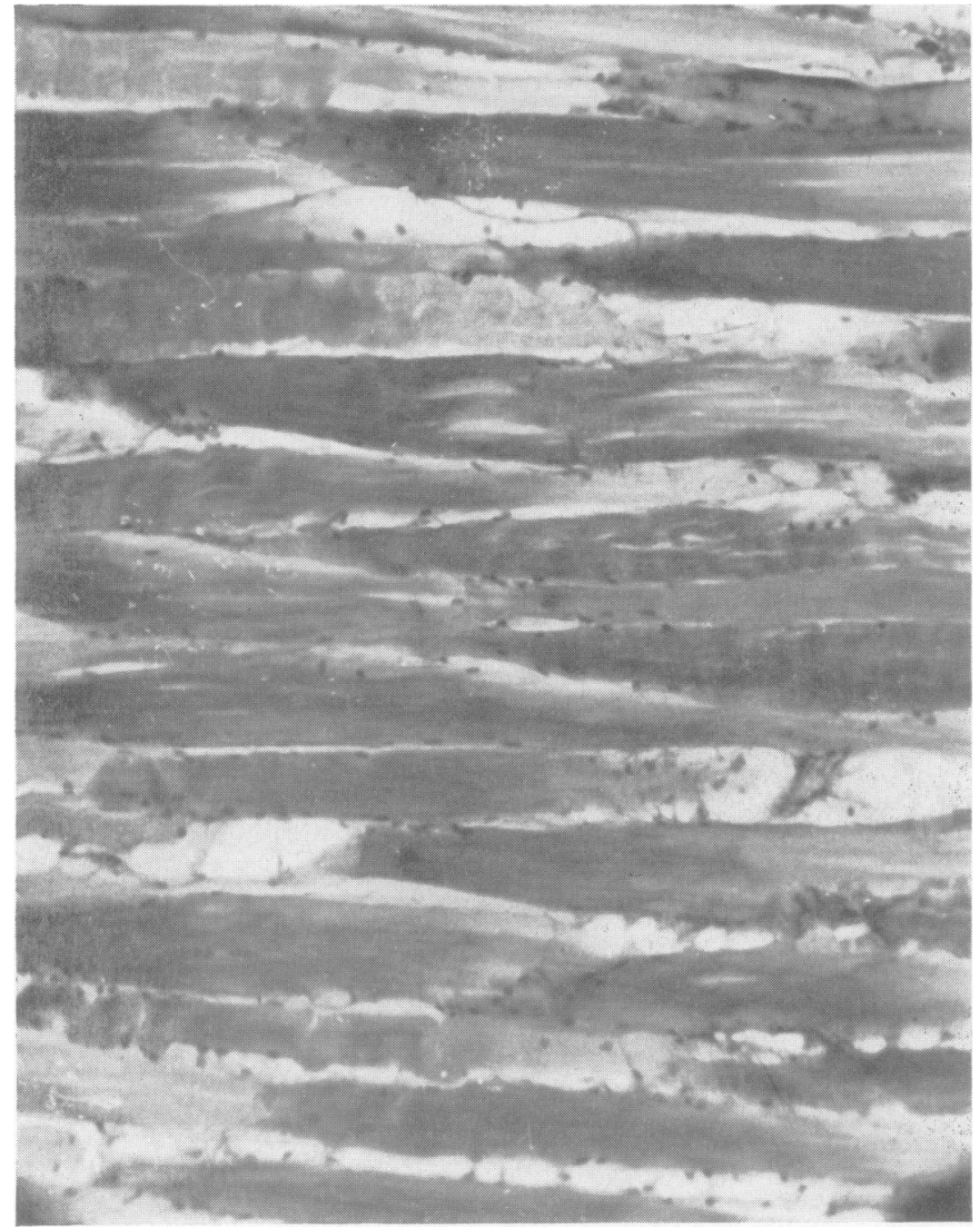

FIG. 5. Longitudinal sections of biopsied muscle, stained periodic acid-Schiff reagent.

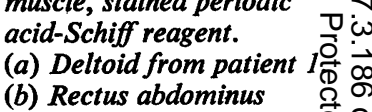
from control. $\times 162$.

centrations of lactate and pyruvate in blood obtained from deep tissues of the forearm, presumably because of the increase in blood flow. Thus an increase in venous blood lactate and pyruvate is not essential for the development of vasodilatation soon after adrenaline infusion is begun. However, Table III shows that the dose of adrenaline used did not increase venous lactate or pyruvate even in the control subject. Barcroft and Cobbold (1956) had previously found that the early increase in blood flow after adrenaline was independent of increase in venous lactate or pyruvate. The present results indicate that the phenomenon still occurs even when release of lactate or pyruvate from muscle close to small blood vessels is probably reduced. Histo-
TABLE IV

FIRST TRIAL OF EFFECT OF GLUCOSE ON EXERCISE TOLERANCE $\begin{array}{ll}\begin{array}{l}\text { Time to First Discomfort } \\ \text { (min.-sec.) }\end{array} & \begin{array}{l}\text { Time to Stopping } \\ \text { (min.-sec.) }\end{array}\end{array}$

No injection

20 ml. normal saline IV

$20 \mathrm{ml} .50 \%$ glucose IV

No injection

chemical examination showed phosphorylase activity to be present in normal amount in the walls of small blood vessels of case 1 of Engel et al. (1963).

ALLEVIATION OF SYMPTOMS BY GLUCOSE AND FRUCTOSE The patient's ability to exercise at a standara rate 


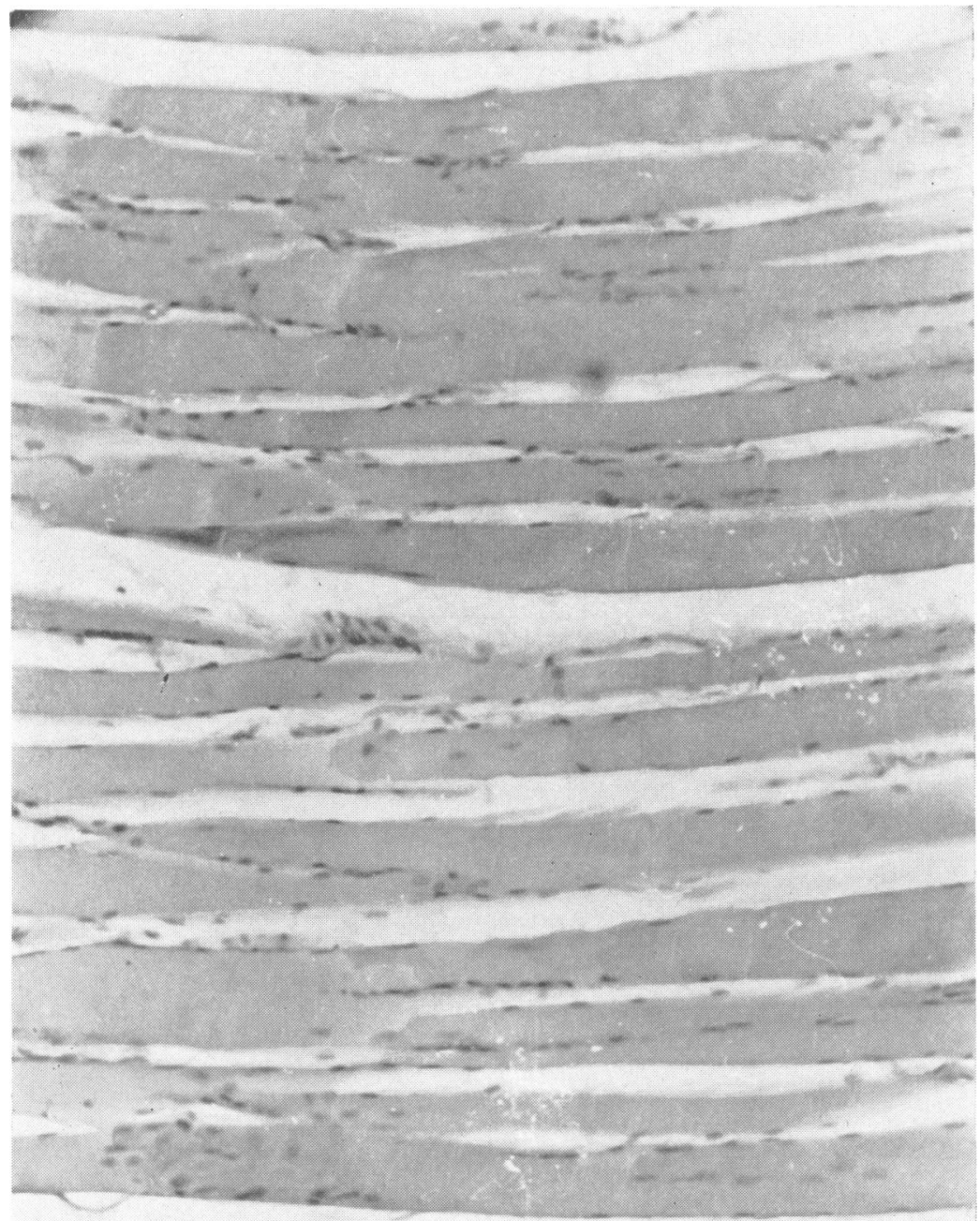

FIG. 5 b.

on a set of steps was measured with and without injection of glucose. He undertook four periods of exercise as shown in Table IV, resting for $15 \mathrm{~min}$. before each. The time intervals to onset of pain and to stopping exercise were measured. After a control period without injection, and a further control period with injection of normal saline, intravenous injection of $10 \mathrm{~g}$. glucose markedly delayed both the onset of pain and the cessation of exercise.

Such improvement in performance after glucose injection has been observed previously (Schmid and Mahler, 1959; Pearson et al., 1961) and so has the similar benefit given by fructose (Pearson and Rimer, 1959; Mellick et al., 1962). Another experiment was done to test the effect of fructose and to try to clarify its mode of action. Exercise ability was now measured in two ways, by walking up and down two steps and by intermittent maximal contraction with the right hand on a dynamometer. The experiment was arranged so that, in a sequence lasting $20 \mathrm{~min}$., first venous blood was drawn and the test injection given intravenously, then maximal forearm dynamometer contractions were made once every two sec. for three min.; venous blood was drawn again; the patient climbed up and down steps until fatigued; and then rested. The rest period lasted roughly $10 \mathrm{~min}$., although its exact length depended upon the duration of step climbing. None of the test injections increased the work done on the dynamometer (Table V) in this intermittent exercise, but step climbing 

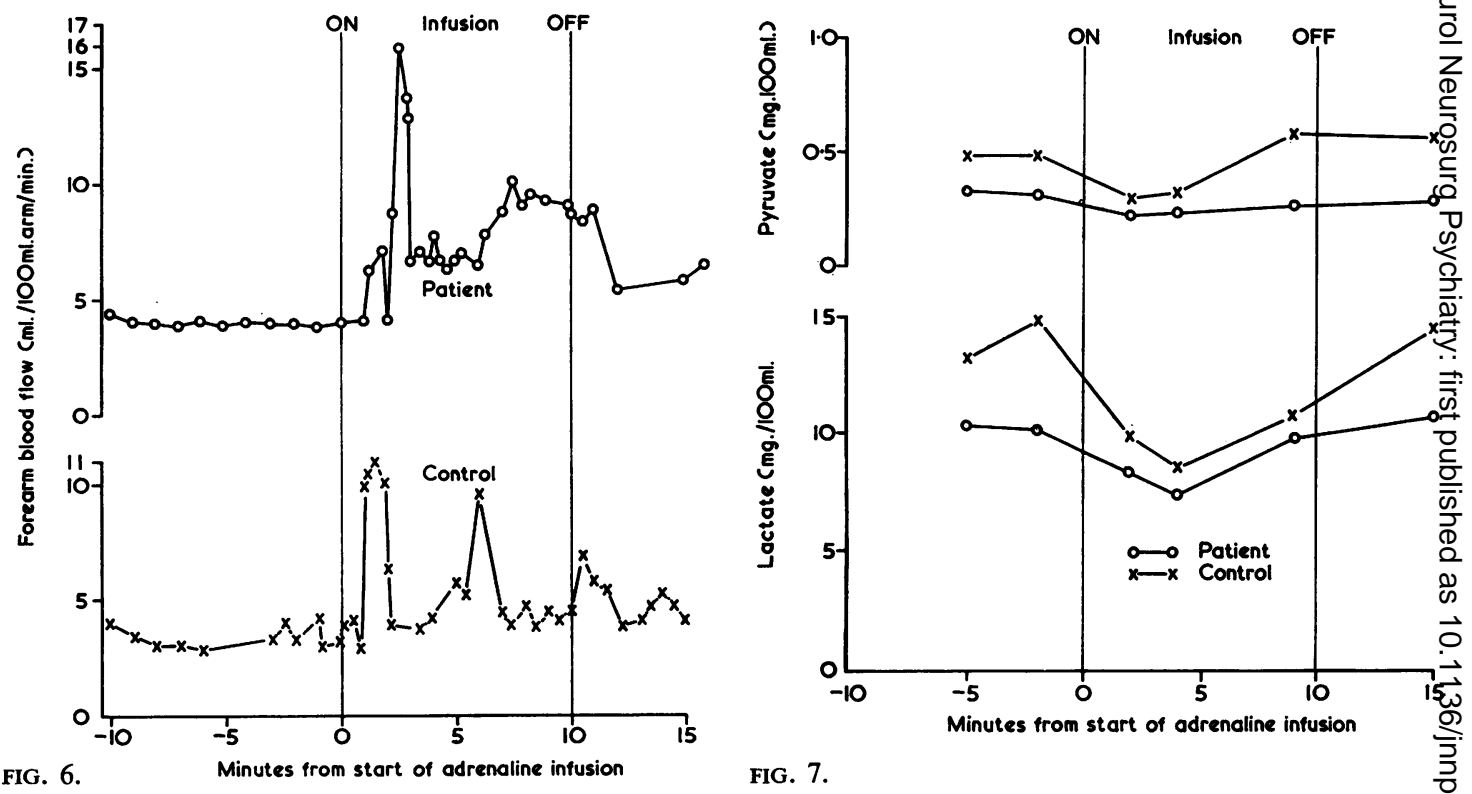

FIG. 6. Infusion of adrenaline showing forearm blood flow when $5 \mu$ g. adrenaline was infused per min. for 10 minutes. 근

FIG. 7. Infusion of adrenaline showing level of venous blood lactate and pyruvate when $5 \mu g$. adrenaline $7 \dot{\alpha} s$ infused per min. for 10 minutes.

TABLE V

Observation periods

Blood glucose (mg./100 ml.) $)^{1}$

Blood fructose (mg./100 ml.) ${ }^{1}$

Time to first pain, walk (sec.)

Time walking continued (sec.)

Steps climbed

EFFECT OF GLUCOSE AND FRUCTOSE ON EXERCISE

Work on dynamometer in first 30 contractions (arbitrary units) 688

$1=$ No injections

\begin{tabular}{|c|c|c|}
\hline 1 & 2 & 3 \\
\hline $\begin{array}{rr}a & c \\
89 & -68\end{array}$ & $\begin{array}{rr}a & c \\
68 & -68\end{array}$ & $\begin{array}{rrr}a & b & c \\
68 & -73 & -60\end{array}$ \\
\hline $\begin{array}{l}\text { a } \\
1-1\end{array}$ & $\begin{array}{l}\text { a } \\
1-1\end{array}$ & $\begin{array}{lcc}a & b & c \\
18 & -12 & -6\end{array}$ \\
\hline $\begin{array}{l}125 \\
170\end{array}$ & $\begin{array}{l}150 \\
210\end{array}$ & $\begin{array}{l}165 \\
214\end{array}$ \\
\hline 45 & 52 & 62 \\
\hline 688 & 631 & 5 \\
\hline
\end{tabular}

$4=20 \mathrm{ml} .40 \%$ fructose

$2=20 \mathrm{ml}$. saline

631

$5=15 \mathrm{ml} .50 \%$ glucose

$5 \mathrm{ml}$. saline

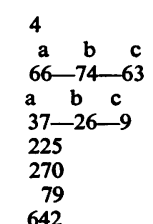

$3=10 \mathrm{ml} .40 \%$ f

$10 \mathrm{ml}$. saline

$6=5 \mathrm{ml} .50 \%$ glucose

$15 \mathrm{ml}$. saline

${ }^{1}$ Value-a $=$ Before dynamometer

b = After dynamometer, before walk

c = After walk and rest

was prolonged after the larger injections of fructose and glucose (fourth and fifth cycles). A blood level of fructose between 18 and $12 \mathrm{mg}$. $/ 100 \mathrm{ml}$. did not prolong the climbing (third cycle). In the sixth cycle, when a small second injection of glucose was given, there was also little or no benefit, which suggests that a transient rise in blood glucose or fructose does not give prolonged benefit.

\section{DISCUSSION}

Further evidence for the genetic basis of McArdle's syndrome is given in the case histories described here, in which a sister of the patient probably has the same condition. Inheritance by an autosomal. recessive gene seems the most likely because the patient's parents, child, and one sister have not beet affected. This mode of inheritance is also the most probable in the other reports of familial involvement. in classical cases (Schmid and Hammaker, $1961 \oint$ Rowland et al., 1963). The present patient resembles those described by McArdle (1951), Schmid an $\$$ Mahler (1959), Pearson et al. (1961), Thomson et al. (1963), and Rowland et al. (1963). He gives. a history of muscle pain on exercise since childhood he has widespread involvement of skeletal muscle and he shows no rise of blood lactate or pyruvate on exercise even with a restricted circulation 
The glycogen content of the muscle is increased and there is no or greatly reduced phosphorylase both histochemically and on assay of a homogenate. There is no evidence of hepatic or cardiac involvement; blood sugar is normal; and glucose or fructose injection increases exercise tolerance.

Of other familial cases, Mahler (Schmid and Mahler (1959)) reported two sisters with the syndrome among the six examples of the condition he had then seen, but no investigation of muscle tissue could be done. The brother and sister described by Engel, Eyerman, and Williams (1963) had a modification of the classical picture suggestive of incomplete penetrance; in neither did symptoms appear until around 50 years of age and both had normal muscle glycogen. The brother had very mild disability; he showed increased blood lactate after exercise, and deficiency of muscle phosphorylase could be shown only by a refinement of the usual histochemical procedure.

Another patient with normal muscle glycogen, but with a clinical history typical of McArdle's syndrome, has been described by Mellick et al. (1962). This patient showed no rise of blood lactate on exercise and an absence of muscle phosphorylase, both histochemically and on incubation in vitro with glucose-1-phosphate. However, as well as lack of increase in muscle glycogen, he showed no improvement in exercise tolerance after $22.5 \mathrm{~g}$. of glucose orally (but the interpretation of this is uncertain since his blood sugar was $122 \mathrm{mg}$. $/ 100 \mathrm{ml}$. before exercise and $78 \mathrm{mg} . / 100 \mathrm{ml}$. at the end of exercise and after the glucose). However, he did improve after oral fructose, when there was a marked rise in blood glucose. Mellick et al. (1962) speculated on the presence of an enzyme defect other than the observed phosphorylase deficiency.

The exact interpretation of 'McArdle's syndrome' must remain uncertain until these variants are understood. McArdle's original patient (1951) was later shown to be defective in skeletal muscle phosphorylase (Mahler and McArdle, 1960). Absence of a rise in lactate and pyruvate on exercise under ischaemic conditions does not necessarily indicate lack of phosphorylase because it has been observed in a 50 -year-old man with a chronic progressive myopathy who had normal skeletal muscle phosphorylase but deficiency of amylo-1.6-glucosidase in muscle and liver (Oliner, Schulman, and Larner, 1961). This patient also had a low fasting blood sugar, impaired glucose tolerance, and no rise of blood glucose after adrenaline or glucagon injection.

To return to a more detailed consideration of Mr. H.K., in some ways his history is surprisingly similar to others described. In childhood races he did well in comparison with other children until his pain began, as did the patient of Pearson et al. (1961). Like McArdle's patient (1951), Mr. H.K. has a very large appetite but is not obese. He describes, and once exhibited, a phenomenon akin to 'second-wind' or, perhaps better, to the 'walking off' of ischaemic pain. His sister also gives a clear description of this phenomenon, which was stressed in the account of Pearson et al. (1961).

On electromyography (McArdle, 1951), Dawson and Merton, recording from an area of local swelling, found electrical silence in muscle painful after exercise. In the patient of Rowland et al. (1963) similar inactivity was found on recording from such muscle (but in which there was no local swelling) on different occasions more than 10 years apart. In Mr. H.K., Dr. G. Rushworth found electrical activity in painful, fatigued muscle, and it persisted for as long as the pain; but he was not recording from a localized swelling. He found nearly normal activity during contractions with the blood supply undisturbed, and this is surprising in view of the widespread histological changes reported by Dr. B. Brownell. The mildness of the patient's symptoms, especially in the arms, is also in contrast to the histology, and one can only speculate whether the latter may herald the approach of the third stage (of muscle wasting with weakness at rest) that Schmid and Mahler (1959) proposed in a sketch of the probable natural history of the condition.

Two possible treatments have been considered. Schmid and Hammaker (1961) suggested that glucagon injection, by raising blood sugar at the expense of liver glycogen, might allow a higher rate of energy expenditure from blood-borne fuel to compensate for the lack of available glycogen within the muscle. However, the benefit from glucagon, although sometimes striking, does not arrest the progression of the disease (Schmid and Hammaker, 1961) and not all patients seem to be helped (Rowland et al., 1963).

Alternatively, hexoses may be given. Oral glucose made McArdle's patient too fat (Mahler and McArdle, 1960); and with it, there is a risk of increasing the rate of glycogen deposition in muscle, and this may be related to necrosis of muscle fibres (Pearson and Rimer, 1959). Fructose has been shown to increase exercise tolerance (Pearson and Rimer, 1959) and has been recommended (Mellick et al., 1962) but only for use just before unusual exertion. There has been discussion of its mode of action by Opie, Evans, and Renold (1962); Wolf (1962); and Opie (1962). In the present case the results are similar to those obtained by Pearson and Rimer (1959) in that improvement occurred at a blood fructose level of $38 \mathrm{mg} . / 100 \mathrm{ml}$; similarly glucose seemed effective only when above a threshold level. 
The improvement with fructose occurred without a simultaneous rise of blood glucose to a level where this itself would have been active, but of course measurements of blood level tell nothing of rate of passage of a substance into a tissue. Nor were any measurements made of pyruvate, lactate, or other catabolic products of fructose that might mediate its effect. Improvement associated with a rise in blood hexose did not outlast it, as shown by a return to the usual disability in period 6 (Table V) so the benefit from fructose seems linked to a high blood fructose level. Fructose is known to be used directly by skeletal muscle (Cori, 1926) but probably in small amounts in comparison to hepatic utilization. However, this relationship may not be the same for muscle that lacks phosphorylase as for normal muscle because changes in metabolite concentrations consequent on the primary defect might lead to alteration of the concentrations of other enzymes.

However, the benefit given to Mr. H.K. by fructose taken orally was so slight in his day-to-day life ( $30 \mathrm{~g}$. taken 20 minutes previously did not prevent pain and incapacity when he hurried for his evening train) that fructose has not been continued, particularly because of the possible risk of increasing muscle glycogen.

Professor Sir Hans Krebs asked if a high-fat, lowcarbohydrate diet would lead to a greater utilization of fatty rather than carbohydrate substance by skeletal muscle with subsequent adaptive increase of enzymic oxidation of fat so that the disability from the deficient breakdown of intrinsic glycogen would be reduced. Mr. H.K. took such a diet as an outpatient for two weeks, without apparent deterioration or improvement on it. He then returned to his preferred food.

In other patients with deficient muscle phosphorylase, it would be worthwhile to study the 'walkingoff' phenomenon in order to determine what is the change that occurs in the exercising muscle a few minutes after exercise starts and which enables exercise then to continue more easily. It would also be interesting to study the distribution of phosphorylase in other tissues; liver phosphorylase has been found to be normal in these patients by in vivo (McArdle, 1951) or in vitro (Schmid and Mahler, 1959) measurements, but this enzyme has not been investigated in adipose tissue, where glycogen is also an important metabolite (Tuerkischer and Wertheimer, 1942).

\section{SUMMARY}

A 51-year-old man is described who has had pain and weakness in the legs on exertion since childhood although he has always been able to prolong indefinitely exercise at a low rate and has no weakness initially in muscle contraction. One sister has $a_{Z}$ very similar history.

Investigation revealed the features associated with McArdle's syndrome (1951). There was no rise of blood lactate or pyruvate levels on exercise, withô circulation free or occluded; skeletal muscle had an ${ }_{0}$ excessive concentration of glycogen; phosphorylase activity was greatly reduced in skeletal muscle on histochemical and muscle homogenate studies; and the ability to exercise was increased by intravenous: injection of glucose or fructose.

The patient is remarkably little incapacitatedo despite disability for over $\mathbf{4 0}$ years and considerable $\bar{O}$ muscle necrosis histologically. The familial incidence $\overline{\bar{p}}$. suggests transmission of the defect by an autosomal $\mathbb{Q}$ recessive gene.

The authors wish to thank Professor Sir George. $\vec{\circ}$ Pickering for his help in the collection and expression of $\overrightarrow{\vec{C}}$ the data presented; Professor H. Barcroft for his help. with the adrenaline experiments; Mr. J. R. P. O'Brien for the cooperation of the Department of Clinical Biochemistry, the Radcliffe Infirmary, in the creatine measure-iv ments and in plasma spectroscopy; Dr. B. Brownell of the.$v$ Department of Neuropathology, the Radcliffe Infirmagy, Oxford, for histological examinations; Dr. G. Rus $\vec{j}-\infty$ worth, the Neurological Research Unit, United Oxfofd Hospitals, for electromyography; Dr. P. Kent, the은 Department of Biochemistry, Oxford University, chemical measurements on muscle tissue; and $\mathrm{Mr}$. $\mathrm{B} . \subseteq$ Matchett for skilled technical assistance. During this wo J. A. Downey was supported by a Life Insurance Medical Research Fund Fellowship.

\section{REFERENCES}

Barcroft, H., and Cobbold, A. F. (1956). J. Physiol. (Lond.), 132, 372. Barker, S. B., and Summerson, W. H. (1941). J. biol. Chem., 138, 535. 긍 Brod, J., and Sirota, J. H. (1948). J. clin. Invest., 27, 645.

Cori, C. F. (1926). J. biol. Chem., 70, 577.

Engel, W. K., Eyerman, E. L., and Williams, H. E. (1963). New Engl. J. Med., 268, 135.

Hockaday, T. D. R. (1961). Biochem. J., 80, 31 P.

Huggett, A. St. G., and Nixon, D. A. (1957). Lancet, 2, 368.

Kreutzer, F. L., Strait, L., and Kerr, W. J. (1948). Arch. intern. Med., 81, 249.

Leloir, L. F., and Cardini, C. E. (1957). J. Amer. chem. Soc., 79, 6340 Lewis, T., and Grant, R. (1925). Heart, 12, 73.

_- Pickering, G. W., and Rothschild, P. (1931). Ibid., 15, 359.

McArdle, B. (1951). Clin. Sci., 10, 13.

Mahler, R. F., and McArdle, B. (1960). Quart. J. Med., 29, 638.

Mellick, R. S., Mahler, R. F., and Hughes, B. P. (1962). Lancet, 15 1045.

Mommaerts, W. F. H. M., Illingworth, B., Pearson, C. M., Guillory, R. J., and Seraydarian, K. (1959). Proc. nat. Acad. Sci. (Wash.), 45, 791.

Mottram, R. F. (1955). J. Physiol. (Lond.), 128, 268.

$\longrightarrow$, and Butterfield, W. J. H. (1961). Proc. roy. Soc. Med., 54, 549. D

Oliner, L., Schulman, M., and Larner, J. (1961). Clin. Res., 9, 243.

Opie, L. H. (1962). Lancet, 2, 1228.

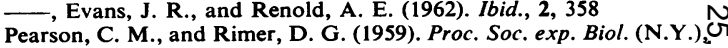
100,671 .

Rimer, D. G., and Mommaerts, W. F. H. M. (1961). Amer. J.C Med., 30, 502.

.


Rowland, L. P., Fahn, S. and Schotland, D. L. (1963). Arch. Neurol. (Chic.), 9, 325.

Schmid, R., and Hammaker, L. (1961). New Engl. J. Med., 264, 223.

—, and Mahler, R. (1959). J. clin. Invest., 38, 2044.

Seifter, S., Dayton, S., Novic, B., and Muntwyler, E. (1950). Arch. Biochem., 25, 191.

Sutherland, E. W., and Wosilait, W. D. (1956). J. biol. Chem., 218, 459.
Takeuchi, T., and Kuriaki, H. (1955). J. Histochem. Cytochem., 3, 153.

Thomson, W. H. S., MacLaurin, J. C., and Prineas, J. W. (1963). J. Neurol. Neurosurg. Psychiat., 26, 60.

Tuerkischer, E., and Wertheimer, E. (1942). J. Physiol. (Lond.), $100,385$.

Weichselbaum, T. E., Margraf, H. W., and Elman, R. (1953). Metabolism, $2,434$.

Wolf, H. P. (1962). Lancet, 2, 937. 